\title{
Cystic Neoplasm
}

National Cancer Institute

\section{Source}

National Cancer Institute. Cystic Neoplasm. NCI Thesaurus. Code C6784.

A benign or malignant neoplasm that contains a single or multiple cystic spaces.

Examples include cystadenoma, mucinous cystadenocarcinoma, and serous cystadenocarcinoma. 